\title{
Microwave Drying of Sawdust for Pellet Production: Kinetic Study under Batch Mode
}

\author{
Sujala Bhattarai ${ }^{1}$, Jae-Heun $\mathrm{Oh}^{2}$, Yun Sung Choi ${ }^{1}$, Kwang Cheol $\mathrm{Oh}^{1}$, Seung Hee Euh ${ }^{1}$, Dae Hyun $\mathrm{Kim}^{1}{ }^{\text {* }}$ \\ ${ }^{1}$ Department of Biosystems Engineering, Kangwon National University, Hyoja 2 Dong, 192-1 Chuncheon, Korea \\ ${ }^{2}$ Forest Practice Research Center, Korea Forest Research Institute, Jikdong-Ri 51, Soheul-Eup, Pocheon-Si, \\ Gyeonggi-Do, 487-821, Korea
}

Received: October $3^{\text {rd }}, 2012$; Revised: December $12^{\text {th }}, 2012$; Accepted: December $23^{\text {th }}, 2012$

\section{Abstract}

Purpose: Drying characteristics of sawdust was studied under batch mode using lab scale microwave dryer. The objective of this study was to investigate the effect of material load and microwave output power on drying characteristics of sawdust. Methods: Material load and microwave output power were varied from 23 to $186 \mathrm{~g}$ and 530 to $370 \mathrm{~W}$ respectively. Different kinetic models were tested to fit the drying rates of sawdust. Similarly, the activation energy was calculated by employing the Arrhenius equation. Results: The drying efficiency increased considerably, whereas the specific energy consumption significantly decreased with increase in material load and microwave output power. The cumulative energy efficiency increased by $9 \%$, and the specific energy consumption decreased by $8 \%$ when the material load was increased from 23 to $186 \mathrm{~g}$. The effective diffusivity increased with decrease in material load and increase in microwave output power. The previously published model gave the best fit for data points with $\mathrm{R}^{2}$ and RMSE values of 0.999 and 0.01 , respectively. Conclusions: The data obtained from this study could be used as a basis for modeling of large scale industrial microwave dryers for the pellet production.

Keywords: Sawdust, Microwave drying, Kinetic study, Pellet production

\begin{tabular}{ll} 
& \multicolumn{1}{c}{ Nomenclature } \\
$D_{e f f}$ & effective diffusion coefficient $\left(\mathrm{m}^{2} \mathrm{~s}^{-1}\right)$ \\
$D_{R}$ & drying rate $\left(\mathrm{g} \mathrm{s}^{-1} \mathrm{~cm}^{-2}\right)$ \\
$E_{a}$ & activation energy $\left(\mathrm{W} \mathrm{g}^{-1}\right)$ \\
$k_{t h}$ & drying rate $\left(\mathrm{s}^{-1}\right)$ \\
$L$ & half the thickness of material $(\mathrm{m})$ \\
$L S D$ & least significant difference \\
$m$ & weight of material $(\mathrm{g})$ \\
$M_{c}$ & moisture content $(\%)$ \\
$M_{e}$ & equilibrium moisture content $(\%)$ \\
$M R$ & moisture ratio \\
$P$ & microwave power (w) \\
$Q_{s}$ & specific energy consumption $\left(\mathrm{MJ} \mathrm{kg}^{-1}\right)$
\end{tabular}

*Comesponding author: Dae Hyun Kim

Tel: +82-33-250-6496; Fax: +82-33-255-6406

E-mail: daekim@kangwon.ac.kr

$\begin{array}{ll}t & \text { time (s) } \\ \eta_{d} & \text { cumulative microwave drying efficiency (\%) }\end{array}$

\section{Introduction}

Sawdust is a commonly used material for the production of wood pellets. Currently, The wet sawdust used for pellet production contains about $30 \%-55 \%$ water on wet basis (w.b.). For production of pellets, manufacturers normally dry the raw material to a water content of about 8\%-15\% before the pelleting process commences (Filbakk et al., 2011). Various types of dryers such as gas fuel dryers, steam dryers, and rotary dryers have been used for drying sawdust. During the drying of sawdust, a large amount of volatile organic compounds (VOC) are released to the atmosphere, and some of them contribute to the 
formation of harmful photo-oxidants. The pellets dried in these conventional dryers have high terpene loss due to a longer residence time, as well as a decreased calorific heating value due to the loss of volatiles during drying. Low VOC emission in drying process could improve the energy content of the sawdust and decrease air pollution in the surroundings of the dryer (Olsson, 2001). The pellet production flow chart and the photo of pilot scale microwave dryer is shown in Figure 1. The conveyor belt is moving between series of magnetron, which generates microwaves (Figure 1(b)).

The use of microwave drying reduces drying time and improves product quality (Metaxas and Meridith, 1993). Microwave drying characteristics are affected by many factors including food dielectric properties, microwave power level, and product geometry (Lu et al. 1998). Microwave energy has been used in a variety of industrial applications, ranging from telecommunication to dielectric heating of foods and other materials. The two microwave frequency bands commonly employed for dielectric heating

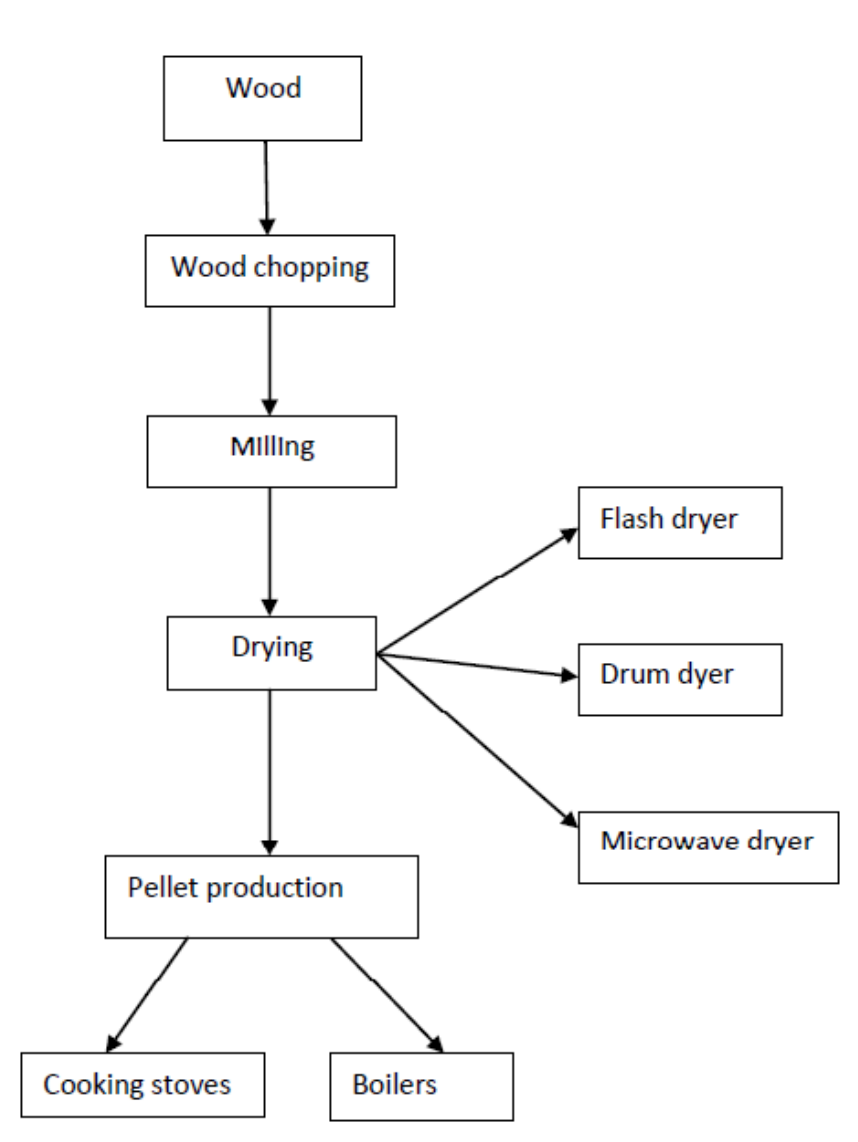

(a) in industry are 915 and $2450 \mathrm{MHz}$. The heating of dielectric material within an electromagnetic field is based on intermolecular friction that arises through ionic conduction and dipolar rotation (White, 1973; Schiffmann, 1997). Numerous studies have been conducted on the microwave drying of woods (Jia and Afzal, 2007; Li et al., 2008), vegetables and fruits (Medeni, 2000; Zang et al., 2006; Rodrigues et al., 2005;), and ores (Taira and Matsui, 2008; Li, 2011). No literature has been reported on the microwave drying of sawdust.

The main objective of this study was to investigate the effect of material load and microwave output power on drying characteristics of sawdust under batch mode. The specific aims of the present work are as follows: (i) determination of the effects of material load and microwave power on the efficiency of microwave drying in terms of drying time, drying rate, drying efficiency and specific energy consumption; (ii) determination of drying kinetics of sawdust by comparing the fitting ability of several drying equations with the most suitable drying

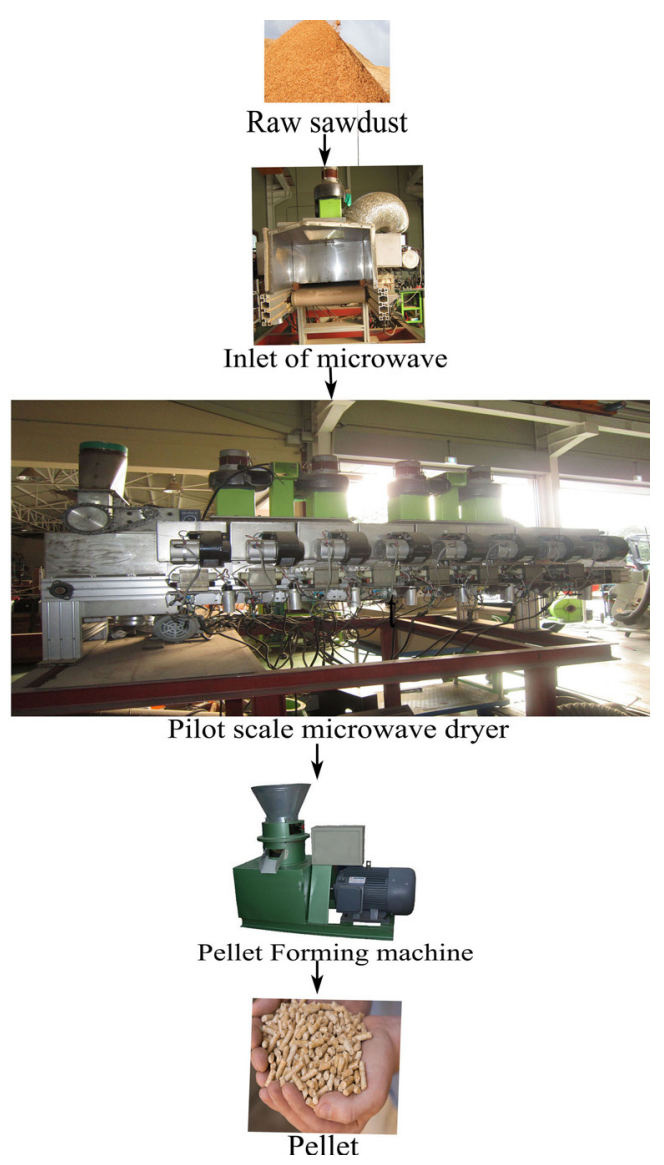

(b)

Figure 1. (a) Flow chart showing conversion of wood biomass waste into energy (b) photograph of pilot scale pellet production system. 
model; (iii) calculation of effective moisture diffusivity and activation energy; and (iv) validation of a relationship between the drying rate constant and the effective moisture diffusivity

\section{Experimental materials}

Sawdust was obtained from Korea Forest Research Institute. The pine tree species Pinus Koraiensis was crushed and the sawdust was obtained. The particle size of the sawdust ranged from $0.0003 \mathrm{~mm}$ to $7 \mathrm{~mm}$. Before the experiments, the moisture content of the sawdust was determined by a digital moisture analyser (Cas CXM50). The sample was properly mixed and 3 replications were done to determine the exact initial moisture content of the sawdust particles. The moisture content of the sawdust was found to be $29.4 \%$ (d.b.).

\section{Drying equipment and experimental procedure}

Drying was performed in a domestic digital microwave oven (Whirlpool, USA) operated at $220 \mathrm{~V}$ with a frequency of $2450 \mathrm{MHz}$. The dimensions of the cavity were $330 \mathrm{~mm}$ (length) $\times 330 \mathrm{~mm}$ (width) $\times 225 \mathrm{~mm}$ (height). The oven was fitted with a $314 \mathrm{~mm}$ diameter turntable. The turntable plays an important role in optimum performance of the oven and reducing the reflected microwave levels onto the magnetron (Khraisheh et al., 1997).

Five different amounts of material loads at constant thickness of $1.7 \mathrm{~cm}$ were investigated in drying experiments $(23.00,56.29,76.00,112.38$, and $186.00 \mathrm{~g})$ with a microwave output power of $530 \mathrm{~W}$. The cross sectional area of the exposed surface of sawdust particles was 43.6, $109.39,142.42,211$, and $492.25 \mathrm{~cm}^{2}$, respectively, at $23.00,56.29,76.00,112.38$, and $186.00 \mathrm{~g}$. In addition, one sample (mass of $50 \mathrm{~g}$ ) was investigated with different microwave output powers $(370,430$, and $530 \mathrm{~W})$. In all experiments, the microwave oven was brought to operating temperature by heating $1000 \mathrm{ml}$ of distilled water in a glass beaker for $5 \mathrm{~min}$ before the first run of the experiment. The sawdust particles were placed on a petri dish in the center of the microwave cavity on the turntable. Moisture loss was measured by removing the dish from the microwave oven and weighing on a $0.01 \mathrm{~g}$ precision digital in every 20 seconds, until no discernible difference between subsequent readings was observed. Three replications of each experiment were performed.

The moisture content, drying rate and moisture ratio of the sawdust were calculated using the following equations
(Li Yu et al., 2011):

$$
M_{c}=\frac{M_{t}}{M} \times 100 \%
$$

where, $M_{c}$ is moisture content in w.b. (\%); $M$ is the total amount of sample (kg); $M_{t}$ is the moisture amount $(\mathrm{kg})$ at the time of $t$;

$$
D_{R}=\frac{W_{s}}{A t}
$$

where, $D_{R}$ is the drying rate $\left.\left(\mathrm{g} \mathrm{s}^{-1} \mathrm{~cm}^{-2}\right)\right) ; W_{s}$ is the weight of material reduced (g); $A$ is the area of drying surface of the sawdust $\left(\mathrm{cm}^{2}\right) ; t$ is the drying time $(\mathrm{s})$;

$$
M R=\frac{M_{t}-M_{e}}{M_{o}-M_{e}}
$$

where, $M R$ is the dimensionless moisture ratio; $M_{t}$ is the moisture content at a specific time (\%); $M_{o}$ is the initial moisture content (\%); $M_{e}$ is the equilibrium moisture content (\%). For the microwave drying, the equilibrium moisture content is assumed to be zero (Ozbek et al., 2007).

\section{Mathematical modeling of microwave drying curves}

To determine the most suitable drying model, the microwave drying curves were fitted to experimental data using five different moisture ratio equations as follows:

- Henderson-pabis index model (Henderson et al., 1961):

$M R=A_{o} \cdot \exp (-k \cdot t)$

- Newton's model (O'Callaghan et al., 1971):

$M R=\exp (-k t)$

- Logarithmic model (Yagcioglu et al., 1961):

$M R=a \exp (-k t)+b$

- Wang and sing (Wang and Singh, 1978):

$M R=1+a t+b t^{2}$ 
- Midilli et al (Midill et al., 2001)

$$
M R=a \exp \left(-k t^{n}\right)+b t
$$

where, $M R$ is the dimensionless moisture ratio; $k$ is the constant drying rate, $\left(\mathrm{s}^{-1}\right) ; t$ is the drying time $(\mathrm{s}) ; A_{o}$ is the index of the dimensionless pre-exponential factor.

The nonlinear regression analysis was done in a statistical program (IBM SPSS statistics 19) to determine constant values of the various drying models. The R-squared, $R M S E_{1}$ and $R M S E_{2}$ were used as a primary criterion to select the best model expressing the microwave drying curves of sawdust.

$$
\mathrm{R}-\text { squared }=1-\frac{\text { Residual sum of squares }}{\text { Corrected sum of squares }}
$$

The values of the residual sum of squares and the corrected sum of squares were determined from ANOVA analysis. $R M S E_{1}$ and $R M S E_{2}$ were calculated as follows (Kim et al., 2007):

$$
R M S E_{1}=\left(\frac{1}{N} \sum_{i=1}^{N} d_{i}^{2}\right)^{\frac{1}{2}}
$$

A few large errors in the sum can produce a significant increase in $\mathrm{RMSE}_{1}$. Therefore, measure using the relative root mean square normalized deviation can also be applied (Kim et al., 2007)

$$
\operatorname{RMSE}_{2}=\left(\frac{1}{N} \sum_{i=1}^{N}\left(\frac{d_{i}}{Y_{i}}\right)^{2}\right)^{\frac{1}{2}}
$$

where, $Y_{i}$ is the measured moisture ratio; $d_{i}$ is the deviation between measured and predicted moisture ratio; $N$ is the number of observations;

\section{Determination of energy efficiency of microwave drying}

The energy efficiency of microwave drying at material load was calculated by two different indices: microwave drying efficiency (\%) and specific energy consumption $\left(\mathrm{MJ} \mathrm{kg}{ }^{-1}\right.$ ). The microwave drying efficiency can be defined as the ratio of heat energy used for evaporating water to the one supplied by the microwave oven (Mousa and Farid, 2002). It can be expressed as:

$$
\eta_{d}=\frac{m_{w} \lambda_{w}}{P \Delta t_{o n}} \times 100
$$

where, $\eta_{d}$ is the microwave drying efficiency (\%); $m_{w}$ is the mass of evaporated water in (kg); $\lambda_{w}$ is the latent heat of vaporization of water in $\left(\mathrm{J} \mathrm{kg}^{-1}\right) ; P$ is the average microwave power (W); and $\Delta t_{\text {on }}$ is the time interval (s). The latent heat of vaporization of water at the evaporating temperature $\left(100^{\circ} \mathrm{C}\right.$ ) was taken as $2257 \mathrm{~kJ} / \mathrm{kg}$ (Hayes, 1987). The power of microwave oven was measured in the laboratory by measuring current and voltage.

The specific energy consumption was calculated as the energy needed to evaporate a unit mass of water (Yongsawatdigul and Gunasekaran, 1996).

$$
Q_{s}=\frac{t_{o n} P \times 10^{-6}}{m_{w}}
$$

Where, $Q_{s}$ is the specific energy consumption $(\mathrm{kJ} / \mathrm{kg})$

\section{Statistical analysis}

The significance of differences in the cumulative drying efficiency, specific energy, and drying rate at different material loads and different experimental conditions was determined using a single factor ANOVA (Analysis of Variance) in Excel 2007 software. If the calculated $F$ value is higher than the tabulated $\mathrm{F}$ value (Fcritical), the Least Significant Difference (LSD) was calculated to judge whether two or more averages were significantly different or not. LSD was calculated at $\alpha=0.05\left(\mathrm{LSD}_{0.05}\right)$ and at $\alpha=0.01$ (LSD ${ }_{0.01}$ ) as follows (Gomez and Gomez, 1984; Little and Hills, 1978):

$$
L S D_{s}=t \alpha \sqrt{\frac{2 s^{2}}{r}}
$$

Where,

$\mathrm{t}_{\alpha}=$ tabulated value chosen for the degree of freedom for error and level of significance $(\alpha)$ desired

$s^{2}=$ mean square for error (MSE)

$r=$ number of replications

\section{Determination of effective diffusivities}

The effective moisture content represents the mechanism of moisture movement within a hygroscopic solid. Diffusivity is assumed to be the only physical mechanism for the transfer of water to material surface during the 
drying process. This can be defined by Fick's second law of diffusion for a slab as follows (Crank, 1975):

$$
\frac{\partial M}{\partial t}=D_{e f f} \frac{\partial M}{\partial x^{2}}
$$

For the solution of the above partial differential equation, the following assumptions can be made:

1. Symmetric mass transfer with respect to the center

2. External resistance to mass transfer is negligible compared to internal resistance

3. Negligible shrinkage and constant diffusion coefficient

The initial and boundary conditions are given as:

Initial condition

$$
\mathrm{t}=0,-\mathrm{L}<\mathrm{x}<\mathrm{L}, \mathrm{M}=\mathrm{M}_{\mathrm{o}}
$$

Boundary conditions

$$
\begin{aligned}
& t>0, x=L, M=M_{e} \\
& t>0, x=-L, M=M_{e}
\end{aligned}
$$

Where, $\mathrm{L}$ is half of the thickness of the material, $\mathrm{M}$ is the moisture content, $\mathrm{M}_{\mathrm{o}}$ is the initial moisture content, $\mathrm{M}_{\mathrm{e}}$ is the equilibrium moisture content, and $t$ is the time.

Since the mass transfer was assumed to be symmetrical (Crank 1975),

$$
\mathrm{t}>0, \mathrm{x}=0, \frac{\partial M}{\partial t}=0
$$

Then, equation (15) can be solved using the separation of variables method (Crank 1975) as follows:

$$
M R=\frac{M_{t}-M_{e}}{M_{o}-M_{e}}=\frac{8}{\pi^{2}} \sum_{n=0}^{\infty} \frac{1}{(2 n+1)^{2}} \exp \left(-\frac{(2 n+1)^{2} D_{e f f} \pi^{2}}{4 L^{2}} t\right)
$$

Using only the first term of the equation (16)

$$
M R=\frac{M_{t}-M_{e}}{M_{o}-M_{e}}=\frac{8}{\pi^{2}} \exp \left(-\frac{D_{e f f} \pi^{2}}{4 L^{2}} t\right)
$$

For the microwave drying process, the equilibrium moisture content can be assumed to be zero ( $\mathrm{Li}$ et al., 2011). The effective moisture diffusivities ( $\left.D_{\text {eff }}\right)$ can be obtained by plotting the experimental data of $\ln (M R)$ versus time. From the slope of this line, the effective diffusivities can be calculated using equation (18) as follows:

$$
\ln (M R)=\ln \left(\frac{8}{\pi^{2}}\right)-\left(\frac{D_{e f f} \pi^{2}}{4 L^{2}}\right)
$$

\section{Results and Discussion}

\section{Effect of sample amount on drying kinetic of sawdust}

The moisture content in microwave drying of sawdust was influenced by the material loads shown in Figure 2(a). The moisture content of sawdust was reduced from $29.4 \%$ to $6 \%$ within 180 to 840 seconds depending on the drying conditions. The initial moisture content of the

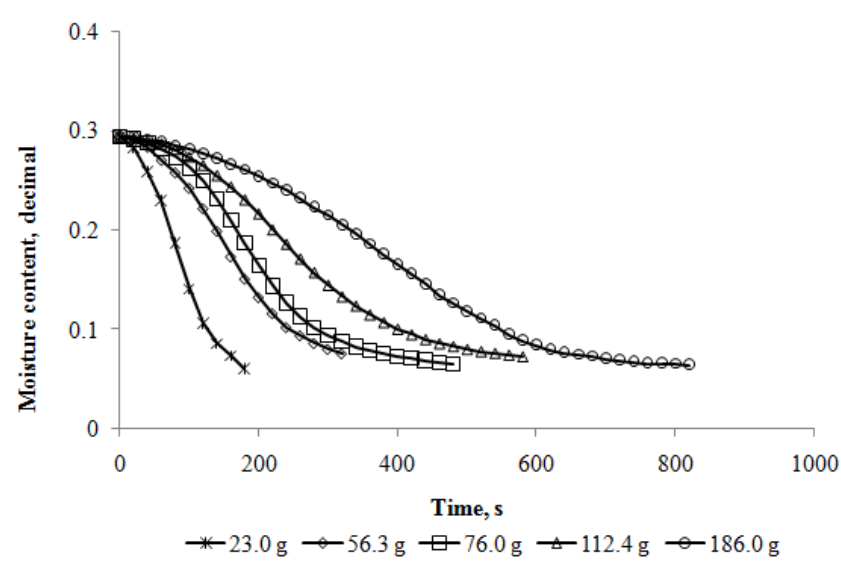

(a)

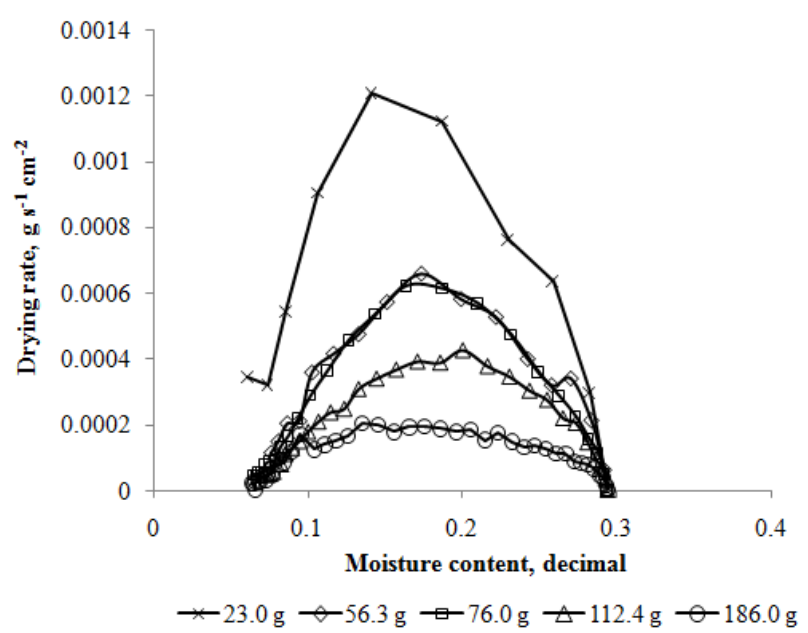

(b)

Figure 2. (a) Relationship between the moisture content and drying time; (b) relationship between the drying rate and moisture content. 
Table 1. (a) Statistical parameters and values of coefficients for each model for different material loads dried at microwave power of $540 \mathrm{~W}$

\begin{tabular}{|c|c|c|c|c|c|c|c|c|c|}
\hline & Model & $\begin{array}{l}\text { Material } \\
\text { loading, g }\end{array}$ & $\begin{array}{c}\text { Drying } \\
\text { coefficient } \\
(\mathrm{k}), \mathrm{s}^{-1}\end{array}$ & $\begin{array}{c}\text { Exponent } \\
\text { (n) }\end{array}$ & $\begin{array}{c}\text { Coefficient } \\
\text { (a) }\end{array}$ & $\begin{array}{l}\text { Coefficient } \\
\text { (b) }\end{array}$ & $\begin{array}{l}\text { Correlation } \\
\text { coefficient }\end{array}$ & $\mathrm{RMSE}_{1}$ & $\mathrm{RMSE}_{2}$ \\
\hline \multirow[t]{5}{*}{1} & Henderson & 23.00 & 0.0090 & & 1.108 & & 0.9470 & 0.0683 & 0.1424 \\
\hline & and & 56.29 & 0.0040 & & 1.124 & & 0.9550 & 0.0573 & 0.1017 \\
\hline & Pabis & 76.00 & 0.0040 & & 1.141 & & 0.9540 & 0.0635 & 0.1166 \\
\hline & model & 112.38 & 0.0030 & & 1.139 & & 0.9633 & 0.0529 & 0.0888 \\
\hline & & 186.00 & 0.0020 & & 1.146 & & 0.9555 & 0.0585 & 0.1108 \\
\hline \multirow[t]{5}{*}{2} & Newton's & 23.00 & 0.0075 & & & & 0.9210 & 0.0833 & 0.1913 \\
\hline & model & 56.29 & 0.0040 & & & & 0.9175 & 0.0769 & 0.1492 \\
\hline & & 76.00 & 0.0030 & & & & 0.9180 & 0.0840 & 0.1579 \\
\hline & & 112.38 & 0.0020 & & & & 0.9240 & 0.0764 & 0.1397 \\
\hline & & 186.00 & 0.0020 & & & & 0.9130 & 0.0805 & 0.1644 \\
\hline \multirow[t]{5}{*}{3} & Wang and & 23.00 & & & -0.0045 & $-5.60 \mathrm{E}-06$ & 0.9705 & 0.0513 & 0.1313 \\
\hline & Singh & 56.29 & & & -0.0020 & $-7.30 \mathrm{E}-07$ & 0.9690 & 0.0466 & 0.1062 \\
\hline & model & 76.00 & & & -0.0025 & $-1.06 \mathrm{E}-07$ & 0.9440 & 0.0690 & 0.1531 \\
\hline & & 112.38 & & & -0.0020 & $-3.64 \mathrm{E}-07$ & 0.9585 & 0.0562 & 0.1236 \\
\hline & & 186.00 & & & -0.0010 & $-2.18 \mathrm{E}-08$ & 0.9610 & 0.0546 & 0.1359 \\
\hline \multirow[t]{5}{*}{4} & Logarithmic & 23.00 & 0.0015 & & 3.280 & -2.2250 & 0.9777 & 0.0448 & 0.1121 \\
\hline & model & 56.29 & 0.0010 & & 3.400 & -2.3290 & 0.9790 & 0.0381 & 0.0859 \\
\hline & & 76.00 & 0.0025 & & 1.370 & -0.2560 & 0.9600 & 0.0573 & 0.1343 \\
\hline & & 112.38 & 0.0015 & & 1.619 & -0.5215 & 0.9740 & 0.0448 & 0.1008 \\
\hline & & 186.00 & 0.0010 & & 2.099 & -1.0085 & 0.9745 & 0.0447 & 0.1138 \\
\hline \multirow[t]{5}{*}{5} & Midilli et al. & 23.00 & 3.38E-05 & 2.0125 & 0.9860 & 0.0010 & 0.9990 & 0.0110 & 0.0265 \\
\hline & & 56.29 & $2.26 \mathrm{E}-05$ & 2.0375 & 0.9815 & 0.0010 & 0.9990 & 0.0068 & 0.0113 \\
\hline & & 76.00 & 2.19E-05 & 2.1480 & 0.9925 & 0.00 & 0.9980 & 0.0130 & 0.0409 \\
\hline & & 112.38 & $1.21 \mathrm{E}-05$ & 1.9975 & 0.9945 & 0.00 & 0.9990 & 0.0061 & 0.0152 \\
\hline & & 186.00 & $2.46 \mathrm{E}-06$ & 2.1210 & 0.9800 & 0.00 & 0.9990 & 0.0076 & 0.0129 \\
\hline
\end{tabular}

sawdust was kept constant; therefore the difference in the drying time was only due to the difference in material loading. The relationship between the drying rate and the moisture content is shown in Figure 2(b). The drying rate was to be found inversely proportional to the obtained material loading as shown in Figure 2(b). This happened because the microwave power density applied per unit mass of dried product decreased with increased material load. The statistical parameters of the five different drying models in the moisture ratios with drying time are given in Table 1(a). Among all of the drying models used in this study, the Midilli model showed the best fit for all the experimental data points, with values of R-squared greater than 0.9990, and RMSE values less than 0.0409. The precision of the Midilli model's results for the comparison of theoretical and experimental values are shown in

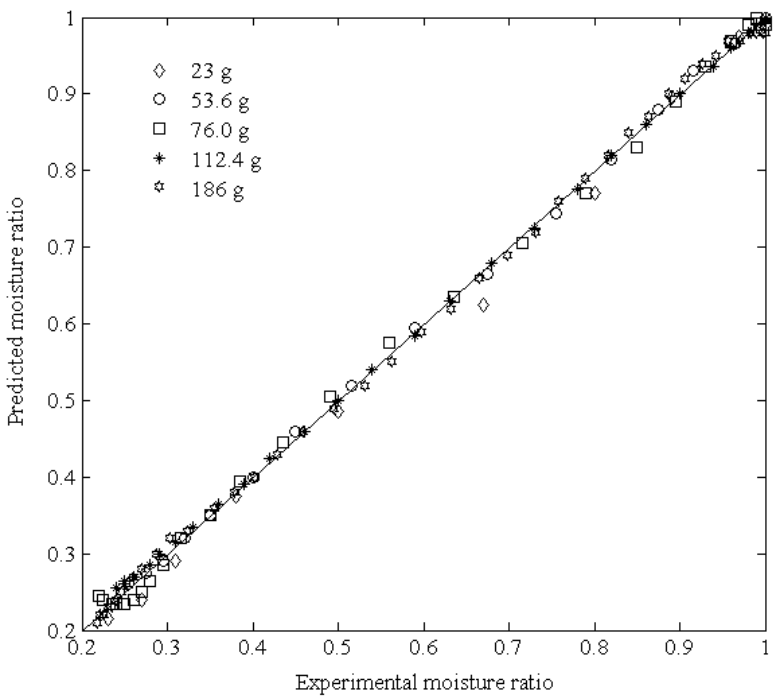

Figure 3. Measured and predicted moisture ratio given by the Midilli model at different material loads. 
Figure 3. The drying coefficient $\mathrm{k}$ decreased with the increase in amount of materials. These results were in good agreement with the drying rate data, which follow similar trends (Figure 2(b)).

Among the three coefficients of Midilli equations $(\mathrm{k}, \mathrm{n}$, and $b$ ), $b$ is almost zero as shown in Table $1(a)$. Therefore, between $\mathrm{n}$ and $\mathrm{k}$, $\mathrm{k}$ was more sensitive with change in amount of sawdust particles than $n$. The regression line was plotted to derive the relationship between the material loading, per square meter area for constant thickness of $1.7 \mathrm{~cm}$, and drying coefficient (calculated from Midilli model). The regression line showed good relationship $\left(R^{2}=0.9611\right)$ between the material loading and drying coefficient ( $\mathrm{k}$ ) as shown in equation (19).

$$
\text { Material loading }\left(\mathrm{g} / \mathrm{cm}^{2}\right)=4.272-11817 \times \mathrm{k}\left(\mathrm{s}^{-1}\right)
$$

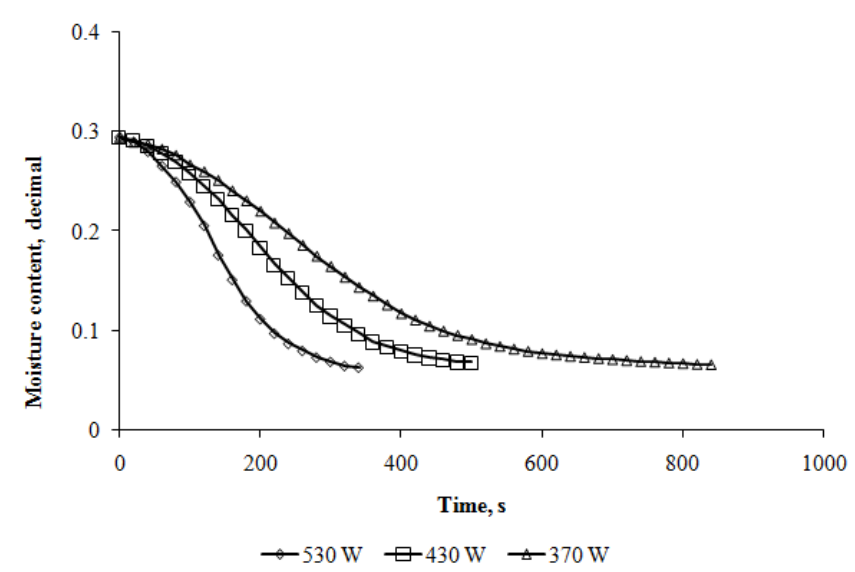

(a)

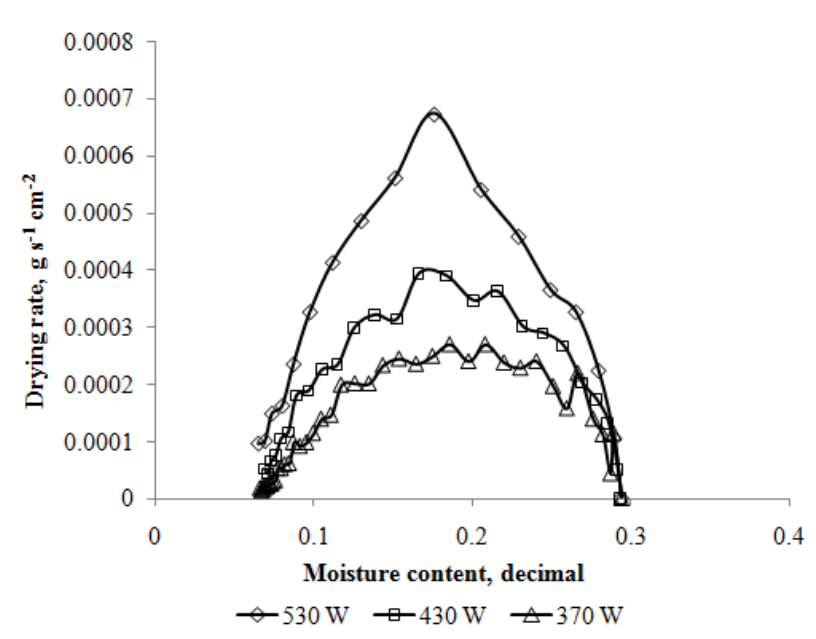

(b)

Figure 4. (a) Relationship between moisture content and drying time; (b) relationship between drying rate and moisture content.

\section{Effect of microwave output power on drying kinetics of sawdust}

The moisture content versus time in drying of sawdust (50 g) at various microwave powers is shown in Figure $4(\mathrm{a})$. The moisture content of sawdust was reduced from $29.4 \%$ to $6 \%$ within 340 to 840 seconds depending on the drying conditions. The initial moisture content of the sawdust was kept constant; therefore the difference in the drying time was only due to the difference in microwave power. Drying time significantly increased when microwave output power was decreased (Figure 4(a)). The relationship between the drying rate and the moisture content is shown in Figure 4(b). The drying rate increased considerably with increased microwave power as shown in Figure 4(b). This happened because the microwave power density applied per unit mass of dried product increased with increased microwave output power.

The statistical parameters of the five different drying models in the moisture ratios with drying time are given in Table 1(b). Among all of the drying models used in this study, the Midilli model showed the best fit for all the experimental data points with values of R-squared value greater than 0.999 and RMSE values less than 0.100 . The measured and predicted moisture ratio given by the Midilli model is shown in Figure 5. Thus, the model represented the experimental values very well in this study. The drying coefficient $\mathrm{k}$ decreased with the increase in amount of materials. These results were in good

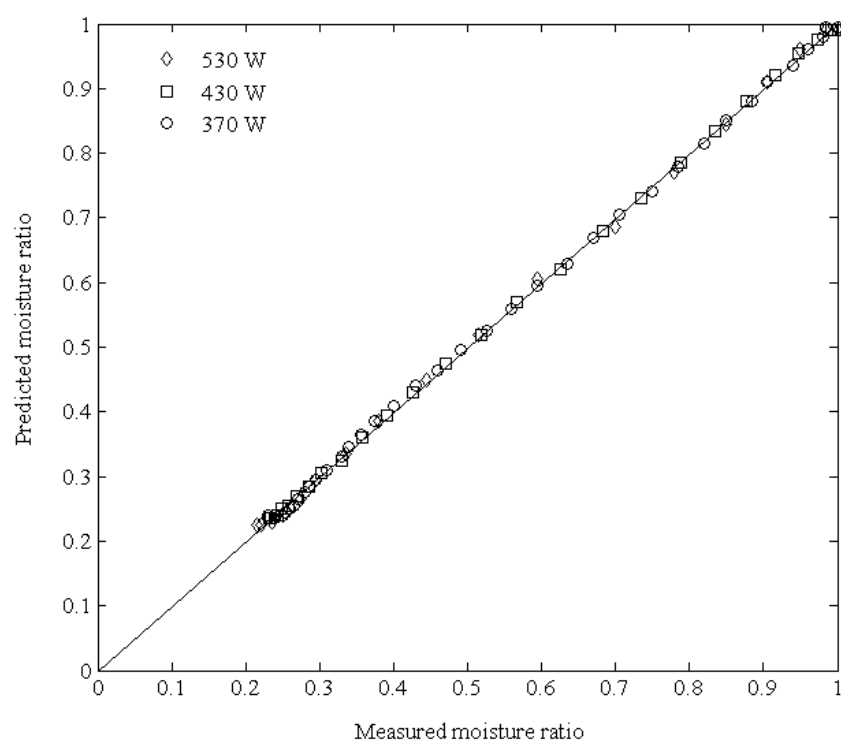

Figure 5. Measured and predicted moisture ratio given by the Midilli et al. model at different microwave output power. 
agreement with the drying rate data, which follow similar trends (Figure 4(b)).

\section{Effect of material load and microwave energy on energy efficiency of microwave drying}

The changes in microwave drying efficiency with moisture content for various material loads were displayed in Figure 6(a). The values of drying efficiency for the sawdust varied between the material loads. It increased with material loading (Figure 6(a)). The microwave drying efficiency was around 3\% during initial period of the drying process, and then sharply increases to moisture content of about $0.15 \mathrm{~kg} / \mathrm{kg}$ (Figure 6(a)). Then, it continued to increase slowly to a moisture content of 0.12 $\mathrm{kg} / \mathrm{kg}$, where the efficiency reached its maximum value and varied within 18 to $24 \%$ depending on the material load ranging from 56.00 to $112.00 \mathrm{~g}$. Below this moisture content, the microwave drying efficiency decreased rapidly.

In the first few seconds, the microwave energy was consumed by the increase in the material temperature, and very little moisture was removed (Figure 2(a) and Figure 4(a)). The initial heating phase during the first few seconds may caused lower drying efficiency values (0.3\%). Similarly, low microwave drying efficiency with low moisture content may be due to the lowered dielectric properties, which is directly proportional to the moisture content. In general, with reduction of moisture content, the ability of the product to absorb microwave energy decreases (Khraishe et al., 1997; Mousa and Farid, 2002).

The heating value of sawdust is about $9.5 \mathrm{MJ} / \mathrm{kg}$ and $15.5 \mathrm{MJ} / \mathrm{kg}$, respectively, at $50 \%$ and $20 \%$ moisture content (FAO, 1990). By interpolation, the heating value of sawdust at $29.4 \%$ was found to be $13.5 \mathrm{MJ} / \mathrm{kg}$. The energy consumed for microwave drying $(350 \mathrm{~W})$ of sawdust varied from 4.15 to $2.34 \mathrm{MJ} / \mathrm{kg}$ as shown in Table 2 .

Table 1. (b) Statistical parameters and values of coefficients for each model for various microwave output power

\begin{tabular}{|c|c|c|c|c|c|c|c|c|c|}
\hline & Model & Power (W) & $\begin{array}{l}\text { Drying } \\
\text { coefficient } \\
(\mathrm{k}), \mathrm{s}^{-1}\end{array}$ & $\begin{array}{l}\text { Exponent } \\
\text { (n) }\end{array}$ & $\begin{array}{c}\text { Coefficient } \\
\text { (a) }\end{array}$ & $\begin{array}{c}\text { Coefficient } \\
\text { (b) }\end{array}$ & R Squared & $\mathrm{RMSE}_{1}$ & $\mathrm{RMSE}_{2}$ \\
\hline \multirow[t]{3}{*}{1} & Henderson & 530 & 0.005 & & 1.123 & & 0.9625 & 0.0554 & 0.1011 \\
\hline & and Pabis & 430 & 0.003 & & 1.107 & & 0.9760 & 0.0470 & 0.0841 \\
\hline & Model & 370 & 0.002 & & 1.090 & & 0.9770 & 0.0399 & 0.1080 \\
\hline \multirow[t]{3}{*}{2} & Newton's & 530 & 0.004 & & & & 0.9330 & 0.0741 & 0.1519 \\
\hline & Model & 430 & 0.003 & & & & 0.9350 & 0.0669 & 0.1300 \\
\hline & & 370 & 0.002 & & & & 0.9620 & 0.0515 & 0.1110 \\
\hline \multirow[t]{3}{*}{3} & Wang and & 530 & & & -0.003 & $1.95 \mathrm{E}-06$ & 0.9640 & 0.0544 & 0.1275 \\
\hline & Singh & 430 & & & -0.002 & 1.72E-06 & 0.9675 & 0.0489 & 0.1156 \\
\hline & Model & 370 & & & -0.002 & 9.99E-07 & 0.9740 & 0.0427 & 0.0870 \\
\hline \multirow[t]{3}{*}{4} & Logarithmin & 530 & 0.003 & 1.5390 & & -0.4550 & 0.9740 & 0.0467 & 0.1153 \\
\hline & Model & 430 & 0.002 & 1.7115 & & -0.6265 & 0.9775 & 0.0404 & 0.0989 \\
\hline & & 370 & 0.002 & 1.0685 & & -0.0150 & 0.9760 & 0.0398 & 0.0988 \\
\hline \multirow[t]{3}{*}{5} & Midilli et al. & 530 & 3.92E-05 & 1.9670 & 0.990 & 0.001 & 0.9990 & 0.0079 & 0.0206 \\
\hline & & 430 & 3.33E-05 & 1.9135 & 0.990 & 0 & 0.9990 & 0.0038 & 0.0072 \\
\hline & & 370 & 2.74E-05 & 0.6910 & 0.990 & 0 & 0.9990 & 0.0065 & 0.0213 \\
\hline
\end{tabular}

Table 2. Energy required for drying and heating value of sawdust

\begin{tabular}{ccccc} 
Weight, $g$ & Drying time, $\mathrm{s}$ & Energy, J $(\mathrm{P} \Delta \mathrm{t})$ & Energy, MJ/kg & Sawdust heating value, MJ/kg \\
23.00 & 180 & 95400 & 4.15 & 13.5 \\
56.29 & 320 & 169600 & 3.01 & 13.5 \\
76.00 & 380 & 201400 & 2.65 & 13.5 \\
112.38 & 500 & 265000 & 2.36 & 13.5 \\
186.00 & 820 & 434600 & 2.34 & 13.5 \\
\hline
\end{tabular}


Therefore, the results implies that energy required for drying of sawdust was 3 times less than the heating value of sawdust.

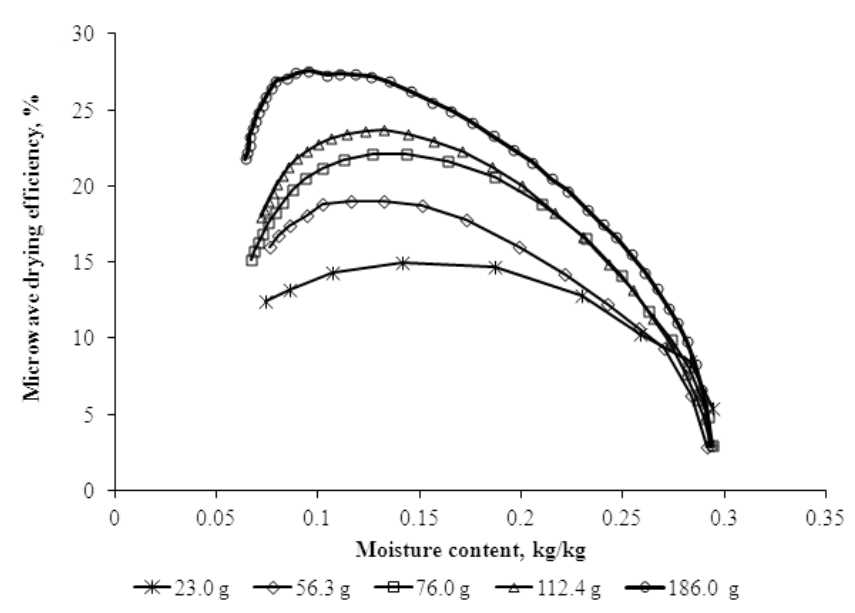

(a)

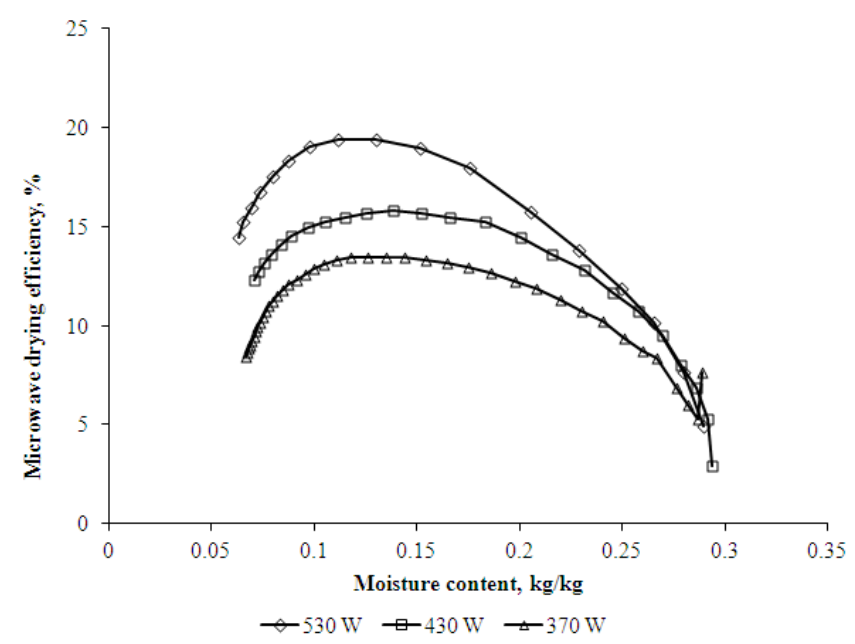

(b)

Figure 6. Microwave drying efficiency versus moisture content (a) at different material loads; (b) at different microwave output power.
The cumulative drying efficiency values were calculated as the averaged energy consumption for water evaporation divided by the supplied microwave energy in the total power-on time $t_{\text {on }}(\mathrm{s})$. The cumulative drying efficiencies were calculated as $12.48 \%, 16.32 \%, 19.49 \%, 21.24 \%$, and $21.45 \%$, for the material loads of $23.00,56.29,76.00$, 112.38 , and $186.00 \mathrm{~g}$, respectively. Although there was a significant reduction in microwave drying efficiency in the final stages of the drying process (Figure 6(a)), the cumulative drying efficiencies were still higher. A least significant difference (LSD) test was performed to determine the significant difference between the cumulative drying efficiencies at different material loading, which is shown in Table 3; the results of the LSD are given in Table 4. The cumulative drying efficiency significantly increased with the material loading rate. As the amount of load increases, the reflection loss and cavity loss are minimized, which in turn increases the efficiency of power absorption (Khraisheh et al., 1997; Mousa and Farid, 2002).

The specific energy consumption values were 18.09, 13.82, 11.58, 10.62 and $10.53 \mathrm{MJ} \mathrm{kg}^{-1}$ for the material loads of 23.0, 56.3, 76.0, 112.4 and $186.0 \mathrm{~g}$, respectively. The specific energy consumption significantly decreased with increase in material load. With increase in the material load from 23.0 to $186.0 \mathrm{~g}$, the specific energy consumption reduced by $8.00 \mathrm{MJ} \mathrm{kg}^{-1}$. The intensity of heat generation is proportional to the amount of moisture content of the material (Araszkiewicz et al., 2004), therefore, the greater amount of water remaining inside the material provided higher drying efficiency and lower specific energy consumption values. The specific energy consumption values for peppermint were reported as 10.00, 8.64 and 4.84 MJ kg-1 by Bushbeck et al. (1967), Muller et al. (1989) and Soysal and Oztekin (2001),

Table 3. Summary of the least significant difference (LSD) values at different material loading

\begin{tabular}{|c|c|c|c|c|c|c|c|c|}
\hline \multirow{2}{*}{ Parameters } & \multirow{2}{*}{ Units } & \multicolumn{2}{|c|}{ LSD } & \multirow[t]{2}{*}{$\mathrm{F}$ value } & \multirow[t]{2}{*}{ MSE } & \multirow[t]{2}{*}{ P-value } & \multicolumn{2}{|c|}{ F critical } \\
\hline & & $\alpha=0.05$ & $\alpha=0.01$ & & & & $\alpha=0.05$ & $\alpha=0.01$ \\
\hline \multicolumn{9}{|c|}{ At different material load } \\
\hline Cumulative efficiency & $\%$ & 1.23 & 1.78 & 96.73 & 0.29 & 1.18E-05 & 5.19 & 11.39 \\
\hline Specific energy & $\mathrm{MJ} / \mathrm{kg}$ & 0.73 & 1.054 & 191.52 & 0.11 & 1.18E-05 & 5.19 & 11.39 \\
\hline Drying rate & $\mathrm{kg} / \mathrm{s}$ & $2.90 \mathrm{E}-06$ & 4.17E-06 & 96.73 & $1.65 \mathrm{E}-12$ & $6.38 \mathrm{E}-05$ & 5.19 & 11.39 \\
\hline \multicolumn{9}{|c|}{ At different microwave output power } \\
\hline Cumulative efficiency & $\%$ & 3.45 & 5.77 & 16.17 & 2.94 & 0.02 & 9.55 & 30.82 \\
\hline Specific energy & $\mathrm{MJ} / \mathrm{kg}$ & 0.05 & 0.76 & 377.20 & 0.05 & 0.00 & 5.19 & 30.82 \\
\hline Drying rate & $\mathrm{kg} / \mathrm{s}$ & 1.07E-06 & 4.32E-06 & 741.99 & $2.8 \mathrm{E}-13$ & 9.06E-05 & 9.55 & 30.82 \\
\hline
\end{tabular}


Table 4. Results of LSD analysis

\begin{tabular}{|c|c|c|c|c|c|}
\hline \multicolumn{6}{|c|}{ Cumulative efficiency (\%) } \\
\hline Load (g) & 23 & 56.29 & 76 & 112.38 & 186 \\
\hline 23 & - & - & - & - & - \\
\hline 56.29 & VSD & - & - & - & - \\
\hline 76 & VSD & VSD & - & - & - \\
\hline 112.38 & VSD & VSD & VSD & - & - \\
\hline 186 & VSD & VSD & VSD & VSD & - \\
\hline \multicolumn{6}{|c|}{ Cumulative efficiency (\%) } \\
\hline Power (W) & 530 & 430 & 370 & & \\
\hline 530 & - & - & - & & \\
\hline 430 & NSD & - & - & & \\
\hline 370 & VSD & SD & - & & \\
\hline \multicolumn{6}{|c|}{ Specific energy (MJ/kg) } \\
\hline Load (g) & 23 & 56.29 & 76 & 112.38 & 186 \\
\hline 23 & - & - & - & - & - \\
\hline 56.29 & VSD & - & - & - & - \\
\hline 76 & VSD & VSD & - & - & - \\
\hline 112.38 & VSD & VSD & SD & - & - \\
\hline 186 & VSD & VSD & SD & NSD & - \\
\hline Power (W) & 530 & 430 & 370 & & \\
\hline 530 & - & - & - & & \\
\hline 430 & VSD & - & - & & \\
\hline 370 & VSD & VSD & - & & \\
\hline \multicolumn{6}{|c|}{ Drying rate $(\mathrm{kg} / \mathrm{s})$} \\
\hline Load (g) & 23 & 56.29 & 76 & 112.38 & 186 \\
\hline 23 & - & - & - & - & - \\
\hline 56.29 & VSD & - & - & - & - \\
\hline 76 & VSD & VSD & - & - & - \\
\hline 112.38 & VSD & VSD & SD & - & - \\
\hline 186 & VSD & VSD & VSD & SD & - \\
\hline Power (W) & 530 & 430 & 370 & & \\
\hline 530 & - & - & - & & \\
\hline 430 & VSD & - & - & & \\
\hline 370 & VSD & VSD & VSD & & \\
\hline
\end{tabular}

NSD: No significance differences

SD: Significant difference

VSD: Very significant difference

respectively.

The changes in microwave drying efficiency with moisture content for different microwave output power is shown in Figure 6(b). The drying efficiency increased with increased microwave output power (Figure 6(b)). Drying efficiency at the final stages of the drying process decreased significantly (Figure 6(b)). Cumulative drying efficiencies were calculated as $14.43 \%, 11.85 \%$ and $8.26 \%$ for microwave output power of 530, 430 and 370 $\mathrm{W}$, respectively. The specific energy consumption values 
were $15.65,19.05$ and $27.33 \mathrm{MJ} \mathrm{kg}^{-1}$ for microwave output power of 530, 430 and $370 \mathrm{~g}$, respectively. The specific energy consumption significantly lower in higher microwave power.

\section{Moisture diffusivity values}

The effective moisture diffusivity of the sawdust particles for microwave drying at various sample amounts is shown in Table 5 . The effective moisture diffusivity of sawdust decreased from $8.76 \times 10^{-7}$ to $1.92 \times 10^{-7} \mathrm{~m}^{2} / \mathrm{s}$ as the sample amount increased from 23 to $186 \mathrm{~g}$. Chen et al. (2012) performed experiments on poplar sawdust and calculated the effective moisture diffusivity by thermogravimetric method in the range of $9.38 \times 10^{-10}$ to 1.38 $\times 10^{-10} \mathrm{~m}^{2} / \mathrm{s}$, which were lower than the values obtained in this study. No documentation was found in the literature, considering the effect of sample amount on effective moisture diffusivity for microwave drying of sawdust particles.

The effective moisture diffusivity of the sawdust particles for microwave drying at various microwave output power is also shown in Table 5. The effective moisture diffusivity of the sawdust decreased from $4.157 \times 10^{-7}$ to $1.587 \times 10^{-7}$ $\mathrm{m}^{2} / \mathrm{s}$ as the microwave output power decreased from 530 to $370 \mathrm{~W}$.

\section{Estimation of Activation Energy}

For the estimation of the activation energy, the Arrhenius equation was modified and used to illustrate the relationship between the kinetic rate constant and the ratio of the microwave power to the sample amount. The dependence of the kinetic rate constant on the ratio of microwave

Table 5. The estimated effective moisture diffusivity at different material loads for the microwave power of $530 \mathrm{~W}$ and at different microwave output power

\begin{tabular}{cccc} 
Material load, $g$ & Slope & Deff, $\mathrm{m}^{2} \mathrm{~s}^{-1}$ & R-squared \\
\hline 23.00 & 0.0096 & $8.76303 \mathrm{E}-07$ & 0.9717 \\
\hline 56.30 & 0.0048 & $4.38152 \mathrm{E}-07$ & 0.9663 \\
76.00 & 0.0043 & $3.92511 \mathrm{E}-07$ & 0.9560 \\
\hline 112.38 & 0.0027 & $2.46460 \mathrm{E}-07$ & 0.9351 \\
\hline 186.00 & 0.0021 & $1.91691 \mathrm{E}-07$ & 0.9713 \\
\hline Power, W & Slope & Deff, $\mathrm{m}^{2} \mathrm{~s}^{-1}$ & R-squared \\
\hline 530 & 0.0055 & $4.15747 \mathrm{E}-07$ & 0.9754 \\
\hline 430 & 0.0035 & $2.64566 \mathrm{E}-07$ & 0.9816 \\
\hline 370 & 0.0021 & $1.5874 \mathrm{E}-07$ & 0.9646 \\
\hline
\end{tabular}

output power to sample amount was represented with an exponential equation (20) given by Dadali et al. (2007):

$$
k=k_{o} \exp \left(\frac{-E_{a} \times m}{P}\right)
$$

where, $k$ is the drying rate constant obtained using the Midilli et al. model $\left(\mathrm{s}^{-1}\right), k_{o}$ is the pre-exponential constant $\left(\mathrm{s}^{-1}\right), E_{a}$ is the activation energy $\left(\mathrm{W} \mathrm{g}^{-1}\right), P$ is microwave output power (W), and $m$ is the mass of raw sample (g). Nonlinear regression analysis was applied to calculate the values of $E_{a}$ and $k_{o}$ by employing the values of $k$ and $\mathrm{m} / P . E_{a}$ and $k_{o}$ were found to be $6.136 \mathrm{~W} / \mathrm{g}$ and $4.5 \times 10^{-5}$ $1 / \mathrm{s}$, respectively, with an $R^{2}$ value of 0.99 .

\section{Effect of material loading on effective moisture diffusivity}

This study was carried out to predict the relationship between the effective moisture diffusivity and the ratio of microwave output power to sample amount. To determine the dependence of the effective moisture diffusivity on the ratio of microwave output power to sample amount, an Arrhenius type exponential model, equation (21), derived by Dadali et al. (2007) was used:

$$
D_{e f f}=D_{o} \exp \left(\frac{-E_{a} \times m}{P}\right)
$$

where, $D_{\text {eff }}$ is the effective moisture diffusivity $\left(\mathrm{m}^{2} / \mathrm{s}\right), D_{o}$ is the pre-exponential factor $\left(\mathrm{m}^{2} / \mathrm{s}\right), E_{a}$ is the activation energy $(\mathrm{W} / \mathrm{g}), P$ is microwave output power $(\mathrm{W})$ and $m$ is the mass of the sample (g). Nonlinear regression analysis was applied to calculate the values of $E_{a}$ and $D_{o}$ by employing the values of $D_{\text {eff }}$ and $m / P$. From the nonlinear regression analysis, $E_{a}$ and $k_{o}$ were respectively found to be $7.37 \mathrm{~W} / \mathrm{g}$ and $1.15 \times 10^{-6}$, with a $\mathrm{R}^{2}$ of 0.96 . Thus, the value of $E_{a}$ obtained from this study was slightly greater $(1.2 \mathrm{~W} / \mathrm{g})$ than the value $(6.136 \mathrm{~W} / \mathrm{g})$ obtained from the equation (20).

\section{The relationship between drying rate constant and effective moisture diffusivity}

The relationship between the drying rate constant and the effective moisture diffusivity, equation (22) was derived using equations (20) and (21) with the assumption that $E_{a}$ values were same in both equations. The theoretical values of $k_{t h}$ and $\left(D_{e f f}\right)_{\text {th }}$ obtained from equations (20) and 


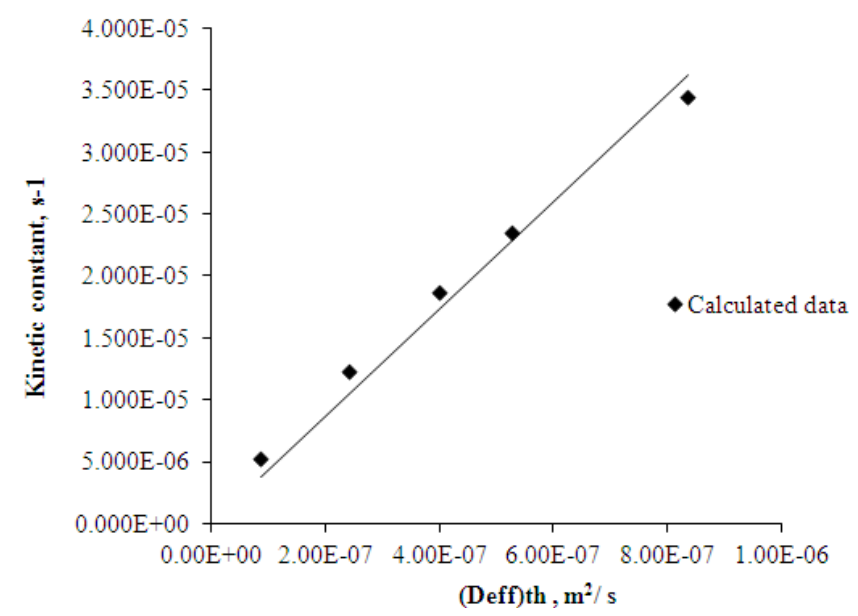

Figure 7. Theoretical values of drying rate versus theoretical values of effective moisture diffusivity.

(21) were fitted to equation (22) with $\mathrm{R}^{2} 0.98$ as shown in Figure 7. The value of constant $A$ was obtained as $43.39 \mathrm{~m}^{2}$.

$$
k_{t h}=A\left(D_{e f f}\right)_{t h}
$$

\section{Conclusions}

The microwave drying characteristics of sawdust were studied using lab scale microwave dryer. The effective moisture diffusivities were found to be in the range of $8.76 \times 10^{-7}$ to $1.92 \times 10^{-7} \mathrm{~m}^{2} / \mathrm{s}$, increasing with decrease mass and $1.56 \times 10^{-7}$ to $4.16 \times 10^{-7} \mathrm{~m}^{2} / \mathrm{s}$, increasing with increased microwave power. Energy activation values estimated from diffusivity data were closed to the energy activation values from drying kinetics data. Drying rate constant and effective moisture diffusivity values showed linear relationships. The Midilli model was considered adequate to describe the drying behavior of the sawdust. The heating value of the sawdust was found to be 3 times higher than the energy consumed for microwave drying; it indicates that microwave drying method could be feasible for drying of sawdust for pellet production. Additionally, the microwave drying could be the more efficient in terms of quality control and drying time compared to other traditional drying methods. The results obtained from this study could be used as a basis for modeling of large scale industrial microwave dryers for the pellet production.

\section{Conflict of Interest}

No potential conflict of interest relevant to this article was reported.

\section{References}

Araszkiewicz, M., A. Koziol, A. Oskwarek and M. Lupinski. 2004. Microwave drying of porous materials. Drying Technology 22(10):2331-2341.

Bushbeck, E., E. Keiner and J. Klinner. 1967. Trocknungsphysikalische and warmetechnische Untersuchung zur Trocknung von Pfefferminze. [Physical and thermal properties effecting drying characteristics of peppermint.] Archiv für Landtechnik 2:163-200.

Chen, D., Y. Zheng and X. Zhu. 2012. Determination of effective moisture diffusivity and drying kinetics of popular sawdust by thermo gravimetric analysis under isothermal condition. Bioresource Technology 107: 451-455.

Crank, J. 1975. The mathematics of Diffusion, $2^{\text {nd }}$ Ed., Clarendon Press, Oxford, UK.

Dadali, G., E. Demirhan and B. Ozbek. 2007. Microwave heat treatment of spinach, Drying kinetics and effective moisture diffusivity. Drying Technology 25(10):17031712.

FAO, 1990. Energy conservation in the mechanical forest industries.

Filbakk, T., G. Skjevrak, O. Dibdiakova and J. Jirjis. 2011. The influence of storage and drying methods for Scots pine raw material on mechanical pellet properties and production parameters. Fuel Processing Technology 92:871-878.

Gomez, K.A. and A. A. Gomez. 1984. Statistical procedures for agricultural research. John Wiley and Sons, Inc., NY, USA.

Henderson, S.M. and S. Pabis. 1961. Grain drying technology: 1 . Temperature effect on drying coefficient. Journal of Agricultural Engineering Research 6(3): 169-74.

Hayes, G. D. 1987. Food Engineering Data Handbook. Longman Scientific and Technical, England.

Jia, D. H. and M.T. Afzal. 2007. Modeling of moisture diffusion in microwave drying of hardwood. Drying Technology 25(1):449-454.

Kaya, A. and O. Aydin. 2009. An experimental study on drying kinetics of some herbal leaves. Energy Con- 
version and Management 50:118-24.

Khraisheh, M., A. M. Cooper and T. J. R. Magee. 1997. Microwave and air drying I. Fundamental consideration and assumptions for the simplified thermal calculations of volumetric power absorption. Journal of Food Engineering 33:207-219.

Kim, D.H., B.M. Jenkins, T.R. Rumsey, M.W. Yore and N.J. Kim. 2007. Simulation and model validation of a horizontal shallow basin solar concentrator. Solar Energy 81:463-475.

Little, T.M. and F. J. Hills. 1978. Agricultural experimentation: design and analysis. John Wiley and Sons, Inc., NY, USA.

Lix, J., B. G. Zang and W.J. Li. 2008. Microwave-vaccum drying of wood model formulation and verification. Drying Technology 26(10):1382-1387.

Lu, L., J. Tang and L. Liang. 1998. Moisture Distribution in Spherical foods in Microwave Drying, Drying Technology 16 (3-5):503-524.

Maskan, M. 2000. Microwave/air and microwave finish drying of banana. Journal of Food Engineering 44:71-78.

Metaxas, A.C. and R.J. Meredith, 1993. Industrial Microwave Heating. Peter Peregrinus, Ltd. London, UK. pp. 375.

Midilli, A., H. Kucuk and Z. Yapar. 2002. A new model for single layer drying. Drying Techonology 20(7):15031513.

Mousa, N. and M. Farid. 2002. Microwave vacuum drying of banana slices. Drying Technology 20(10):2055-2066.

Müller, J., G. Reisinger and W. Mühlbauer. 1989. Trocknung von Heil-und Gewürzpflanzen mit Solarenergie im Folienge wächshause [Drying of medicinal and aromatic plants in a greenhouse solar dryer]. Landtechnik, 2:58-65.

O'Callaghan. J.R., D. J. Menzies and P.H. Bailey. 1971. Digital simulation of agricultural dryer performance. Journal of Agricultural Engineering Research 16:223244.

Olsson, M. 2001. Trapellets som smaskaligt biobransle. Report Chalmers Univerisity of Technology, Goteborg and STEM.

Ozbek, B. and G. Dadali. 2007. Thin layer drying characteristic and modeling of mint leaves undergoing microwave treatment. Journal of Food Engineering 83:541-9.
Page, G. 1949. Factors influencing the maximum rates of air drying shelled corn in thin layers. MSc thesis, Purdue University, Indiana, USA.

Rodrigues, R., J. Lombrana, M. Kamel and C. Elvira. 2005. Kinetics and quality study of mushroom drying under microwave and vacuum. Drying Technology 23 (9-11): 2197-213.

Schiffmann, R.F. 1997. Principles of industrial microwave and RF heating. In Microwaves: Theory and Application in Materials Processing IV (D.E. Clark, W.H. Sutton and D.A. Lewis, eds.) pp. 41-60, The American Ceramic Society, Westerville, $\mathrm{OH}$.

Soysal, Y. and S. Öztekin. 2001. Technical and economic performance of tray dryer for medicinal and aromatic plants. Journal of Agricultural Engineering Research 79(1):73-79.

Soysal, Y., S. Oztekin and O. Eren. 2006. Microwave drying of parsley: Modelling, Kinetics, and Energy Aspects. Biosystems Engineering 93(4):103-413.

Taira, H. and T. Matsui. 2008. High capacity microwave drying of monolithic refractories in Nippon steel corporation, Drying Technology 28(2):143-149.

Wang, C.Y. and R.P. Sing. 1978. A single layer drying equation for rough rice. ASAE Paper No 78-3001, ASAE, St. Joseph, MI.

White, J.R. 1973. Why materials heat. Trans. IMPI 1, paper No 4, 40-65.

Yagcioglu A., A. Degirmencioglu and F. Cagatay. 1999. Drying characteristics of laurel leaves under different drying conditions. Proceedings of the $7^{\text {th }}$ international Congress on Agricultural Mechanization and Energy in Agriculture, pp 565-569. Adana, Turkey, 26-27 May.

Yongsawatdigul, J. and S. Gunasekaran. 1996. Microwavevacuum drying of cranberries:- Part I: energy use and efficiency. J. Food process. Pres. 20:121-143.

Yu, L., L. Ying, Z. Li-bo, P. Jin-hui and L. Chang-long. 2011. Microwave drying characteristics and kinetics of ilmenite, Transactions of nonferrous metals society of China, 202-207.

Zang, M., J. Tang, As. Mujumdar and S.S. Wang. 2006. Trends in microwave related drying of fruits and vegetables. Trends in Food Science and Technology 17:524-34. 